\title{
INFORMAÇÃO E POLÍTICA DE DEFESA: O DEBATE NO BRASIL APÓS 1988
}

\author{
INFORMACIÓN Y POLÍTICA DE DEFENSA: EL DEBATE EN \\ BRASIL A PARTIR DE 1988
}

Angélica Behenck Ceron - angelica.ceron@yahoo.com.br Mestre em Ciência da Informação no Instituto Brasileiro de Informação em Ciência e Tecnologia (IBICT). Bibliotecária do Ministério da Defesa - Comando da Marinha.

Clóvis Ricardo Montenegro de Lima - clovis.mlima@uol.com.br Pós-doutor em Ciência da Informação pelo Instituto Brasileiro de Informação em Ciência e Tecnologia (IBICT). Pesquisador adjunto do IBICT.

\section{RESUMO}

Introdução: Neste trabalho é apresentado como as informações disponíveis sobre Defesa subsidiam a sociedade no debate da política de Defesa, quais os atores que se envolvem no debate e como esses obtêm informação e a transformam no decorrer do debate.

Objetivo: Identificar elementos para discussão do regime de informação subjacente à produção dos estudos de Defesa no Brasil em um contexto democrático.

Metodologia: Os métodos de pesquisa propostos incluem como procedimentos: (1) a análise da legislação sobre Defesa no Brasil de modo a evidenciar o papel da informação nesse contexto; e (2) a análise do campo acadêmico de Defesa no Brasil.

Resultados: Observa-se que a área de Defesa está cada vez mais presente no cenário político brasileiro e nas decisões estratégicas do governo.

Conclusões: Pode-se notar mudança significativa no que se refere ao processo de decisão relativo à Defesa. Embora tenha sido concebida como política de Estado e prevista na Política de Defesa Nacional (PDN) e na Estratégia Nacional de Defesa (END), a política de Defesa tem recebido da sociedade uma participação ainda incipiente, embora haja avanços significativos.

Palavras-chave: Habermas. Política de defesa. Regime de informação. Brasil. 


\section{INTRODUÇÃO}

A discussão da política de Defesa na sociedade é fundamental no contexto democrático. A política de defesa, como toda política de Estado, requer debate com a sociedade, o que ainda é incipiente no Brasil. No entanto, avanços significativos foram obtidos nessa direção, trazendo uma mudança no regime de informação na área da Defesa.

Os métodos de pesquisa propostos incluem como procedimentos: (1) a análise da legislação sobre Defesa no Brasil de modo a evidenciar o papel da informação nesse contexto; e (2) a análise do campo acadêmico de Defesa no Brasil. A análise visa a identificar elementos para discussão do regime de informação subjacente à produção dos estudos de Defesa no Brasil em um contexto democrático.

O problema que se apresenta nesta pesquisa é como as informações disponíveis sobre Defesa subsidiam a sociedade no debate da política de Defesa, quais os atores que se envolvem no debate e como esses obtêm informação e a transformam no decorrer do debate. Apresenta-se, neste quadro, um novo contexto de análise na política de informação, principalmente no que tange ao surgimento de mudanças no regime de informação em Defesa no Brasil.

Observa-se que a área de Defesa está cada vez mais presente no cenário político brasileiro e nas decisões estratégicas do governo. Além disso, pode-se notar mudança significativa no que se refere ao processo de decisão relativo à Defesa. Embora tenha sido concebida como política de Estado e prevista na Política de Defesa Nacional (PDN) e na Estratégia Nacional de Defesa (END), a política de Defesa tem recebido da sociedade uma participação ainda incipiente, embora haja avanços significativos.

Em relação aos conceitos de "Segurança" e "Defesa Nacional" utiliza-se neste artigo a concepção apresentada pela Política de Defesa Nacional (BRASIL, 2005a). "A segurança, em linhas gerais, é a condição em que o Estado, a sociedade ou os indivíduos não se sentem expostos a riscos ou ameaças, enquanto que defesa à ação efetiva para se obter ou manter o grau de segurança desejado" (BRASIL, 2005a).

"Defesa Nacional" é aquela noção concebida pelo PDN, ou seja, "conjunto de medidas e ações do Estado, com ênfase na expressão militar, para a defesa do território, da soberania e dos interesses nacionais contra ameaças preponderantemente externas, 
potenciais ou manifesta". Assim, a Segurança é uma sensação, enquanto a Defesa é o conjunto de ações que geram aquela sensação.

\section{INFORMAÇÃO, ESTADO E SOCIEDADE}

A abordagem teórica nesta pesquisa utiliza-se dos conceitos de mundo da vida e sistema das teorias de Habermas e Luhmann, bem como dos conceitos da política de informação para analisar o debate sobre Defesa no Brasil. A informação no âmbito do debate de Defesa, como atividade típica de Estado, depende da legitimidade advinda do suporte político. A política de informação subsidia a análise do regime de informação nesse processo que envolve a relação do sistema de Defesa com os demais sistemas e o mundo da vida.

Habermas apresenta o conceito de mundo da vida como todo contato social; busca o conceito de mundo da vida na filosofia de Edmund Husserl, o qual conclama o mundo da vida como a esfera imediatamente presente de realizações originárias (HABERMAS, 2002, p. 88).

O saber do mundo da vida caracteriza-se pela imediatez, pela força totalizadora e pela constituição holística desse saber. A partir de garantias que só podemos extrair da experiência, o mundo da vida levanta um muro contra surpresas que provêm da experiência. Se o saber acerca do mundo se define pelo fato de ser adquirido a posteriori, ao passo que o saber acerca da linguagem, considerando relativamente, configura um saber a priori, então o paradoxo pode residir precisamente na integração que existe, no fundo da vida, entre o saber acerca do mundo e o saber acerca da linguagem (HABERMAS, 2002, p. 93-94).

A comunicação no mundo da vida é interrompida quando se choca com o poder econômico e o poder administrativo, meios que não compreendem a linguagem coloquial, pois esses códigos especiais, além de se diferenciarem da linguagem coloquial, foram desmembrados dela. É verdade que a linguagem coloquial forma um horizonte da compreensão; em princípio, ela é capaz de traduzir tudo em todas as linguagens. Porém, ela é incapaz de operacionalizar eficientemente para todos os destinos suas mensagens endereçadas ao comportamento (HABERMAS, 2003, v. 1. p. 82).

$\mathrm{Na}$ análise de Vandenberghe (2010, p. 3) o processo de racionalização do mundo da vida abre passagem para a racionalização do sistema. Com a sociedade mais 
complexa e a distinção dos subsistemas, a coordenação da ação torna-se aos poucos separada do mundo da vida e mediada por meios de controle abstratos como o poder e o dinheiro, que padronizam a situação da ação e regulam as práticas sociais externas. Quando o poder e o dinheiro começam a alastrar-se sobre o mundo da vida, "como senhores coloniais", aparecem nas patologias da sociedade.

Luhmann parte da teoria de Parsons, que especifica firmemente que ação e sistema não poderem ser compreendidos separadamente; ou, em outras palavras: a ação só é possível sob a forma de sistema. A descoberta essencial de Parsons é de que a construção de estruturas sociais se realiza sob a forma de sistemas, e a base da operação sobre a qual esse sistema se constrói é a ação (LUHMANN, 2009, p. 42).

A principal função dos sistemas sociais é a de reduzir a complexidade do mundo de modo que esta possa ser entendida pelas pessoas: a complexidade do mundo é sempre maior do que a complexidade do sistema. O sistema, por sua vez, necessita ter um grau de complexidade menor, de modo a operar no seu meio. Para os sistemas sociais, a redução da complexidade do mundo se apresenta como no problema da dupla contingência.

Na análise de Luhmann (1995, p. 67-68) a informação é sempre informação para um sistema (o que pode incluir vários sistemas ao mesmo tempo). Na categorização de sistemas que podem adquirir e processar informação, é preciso incluir uma característica adicional, a qual indiretamente serve para determinar o conceito de informação. Consideram-se sistemas que operam de modo auto-referencial, portanto, que precisam sempre jogar uma parte de si próprios na alteração de seus próprios estados. Informação reduz a complexidade na medida em que anuncia uma seleção e, desse modo, inclui possibilidades. Pode-se, no entanto, também aumentar a complexidade.

Com a ajuda do processamento da informação comunicativa, a relação entre sistema e o ambiente adquire uma formulação que é compatível com maior complexidade e interdependência. Na Teoria dos Sistemas a informação é apenas possível dentro do sistema, graças à auto-referência e esquemas de interpretação. Pode, contudo, ser atribuída pelo sistema para o ambiente. Informação aparece como uma seleção de um domínio de potencialidades que o sistema, por si mesmo, elabora e segura para ser relevante; mas aparece com uma seleção não do sistema, mas do ambiente que a leva adiante (LUHMANN, 1995, p. 68). 
O conceito de informação deve ser concebido como um conceito com dois lados: a) pelo caráter surpresa, que traz implícita a informação; e b) pelo fato de que a surpresa só existe dentro do conjunto de possibilidades existentes no sistema. Nessa forma, a informação é a seleção que só acontece em uma escala de possibilidades, e que, quando é repetida, perde o caráter surpresa. A informação, em termos teóricos, é entendida como um transfer a partir do meio; no contexto de acoplamento estrutural, trata-se de um acontecimento que se realiza por uma operação efetuada no próprio sistema (LUHMANN, 2009, p. 141-142).

$\mathrm{Na}$ Teoria dos Sistemas, o que se enfatiza é a verdadeira emergência da comunicação. Não existe transmissão de alguma coisa, mas, sim, uma redundância criada no sentido de que a comunicação inventa sua própria memória, que pode ser evocada por diferentes pessoas, e de diferentes maneiras (LUHMANN, 2009, p. 299).

A metáfora da transmissão não é útil, pois implica demasiada ontologia. Ela sugere que o emissor transmite algo que é recebido pelo receptor; mas este não é o caso, simplesmente porque o emissor não dá, no sentido de perder algo. A metáfora do possuir, ter, dar e receber não serve para compreender a comunicação (LUHMANN, 2009, p. 296-297).

A metáfora da transmissão localiza o que é essencial sobre comunicação no ato de transmissão, na elocução. Dirige atenção e demanda por habilidade de quem faz a elocução. No entanto, a elocução é nada mais que uma seleção proposta, uma sugestão. A comunicação emerge apenas na medida em que essa sugestão é melhorada, que seu incentivo é processado (LUHMANN, 1995, p. 139).

A idéia de comunicação na Teoria dos Sistemas contradiz a metáfora da transmissão. Luhmann (2009, p. 294-296) aponta três razões: 1ํ) a comunicação é uma sucessão de efeitos multiplicadores na qual não há perda; $2^{\underline{a}}$ ) não se considera o estado interno dos que participam da comunicação; e $3^{\mathfrak{a}}$ ) a metáfora da transmissão pressupõe simultaneidade entre comunicar e entender, mas graças à escrita é possível a separação espacial e temporal entre transmissão e recepção.

Na metáfora da transmissão se pressupõe que a informação é a mesma tanto para emissor como para receptor. A comunicação nunca é um evento com dois pontos de seleção, nem como um dar e receber (com na metáfora da transmissão), não como a diferença entre informação e elocução. A comunicação emerge apenas se esta última diferença é observada, esperada, entendida e usada como a base para contradição com 
os demais comportamentos. Entretanto, entendimento inclui mais ou menos desentendimentos; mas esses são sempre desentendimentos que podem ser controlados e coordenados.

O Estado pode ser considerado um dos mais influentes sistemas colonizadores do mundo da vida, uma vez que é, por excelência, a instituição que estabelece regulamentos para a sociedade e mantém mecanismos para fazê-la cumprir uma vez que tem o monopólio legal da força. Uma das maiores características do Estado moderno é a expansão da capacidade dos administradores estatais em influenciar até mesmo os mais reservados aspectos da atividade cotidiana.

Habermas (2003, v. 2. p. 63-64) observa que a teoria dos sistemas indica que a sociedade constitui uma rede de sistemas parciais autônomos formando ambientes uns para os outros. A interação entre tais sistemas depende dos modos de operação próprios. Por um lado, o próprio sistema político afirma-se contra todos os outros sistemas funcionais; por outro, passa a prevalecer a compreensão da política centrada no Estado, sugerida pelo modelo liberal. A teoria dos sistemas atribui à formação política da opinião e da vontade, dominada pela concorrência entre os partidos, a um público de cidadãos incorporados ao sistema político, mas desligados do mundo da vida.

Habermas (2003, v. 2. p. 75-78) sintetiza em três pontos o equilíbrio sistêmico: (a) Estado supervisor da negociação de sistemas não hierárquicos. O Estado supervisor exerce uma "política de opções" tal como no planejamento econômico. (b) Política reguladora do sistema tem de se utilizar da linguagem do Direito. O direito funciona como catalisador de transformações internas. (c) Consenso dá a base para o dissenso de tal modo que o dissenso não venha a dissolver o sistema. O consenso se dá por uma linha imaginária o qual o dissenso trabalha para dissolvê-la. Em primeiro lugar, o diálogo dos sistemas funcionais se limita ao fim cognitivo da intensificação reflexiva do saber sistêmico. Em segundo lugar, as regras desse diálogo que regulam as conferências não podem pretender representatividade.

O que é importante destacar na abordagem de Habermas é que não basta o conhecimento especializado produzido pelos sistemas na construção de políticas. São necessários também os aspectos éticos e morais na elaboração de políticas. Esses aspectos têm como fonte o mundo da vida. As políticas devem contemplar aspectos subjacentes ao mundo da vida de modo a ter legitimidade. 
$\mathrm{Na}$ visão de Braman (1994, p. 359) o Estado como sistema possibilita a participação democrática de modo a adequar a sua atuação aos interesses da população. O potencial democrático é a capacidade dos cidadãos de efetivamente participar em processos constituídos socialmente - para o exercício do poder. O processo democrático no qual se está interessado simultaneamente participa em processos auto-organizados em outros níveis, incluindo indivíduos, comunidade e outros sistemas.

Braman (2006, p. 29) aponta que é possível para os Estados fazerem mudança, porque eles são sistemas adaptativos complexos produzidos por interações entre hábitos culturais, leis formais, discurso e modos de organização dentro de um campo em constante mudança de possibilidades. Como outros sistemas adaptativos complexos, Estados respondem às mudanças em recursos e em seus ambientes, com as transformações que vão da menor influência até mudanças significativas na estrutura ou comportamento de todo o caminho para a turbulência, o caos e, talvez, uma completa mudança na natureza do sistema em si mesmo.

González de Gómez (1996, p. 60) igualmente destaca que o Estado, como um observador privilegiado, é capaz realizar operações de totalização e unificação sobre o saber e a informação que se manifesta: nos arquivos, na estatística, na cartografia, nas bibliografias nacionais. Essas operações testemunham uma ação de informação em tendência totalizante, que aspira a reunir e unificar o excedente cognitivo, como se um território de conhecimento alargasse a unidade espaço-tempo do Estado nacional. A essa ação de informação liga-se a busca de códigos unificados tais como linguagens e formatos padronizados, metrologia e normas técnicas.

Em paralelo ao avanço da importância da informação, desenvolve-se um forte debate sobre a atuação do Estado. Esse debate é influenciado pelo avanço tanto de idéias neoconservadoras, quanto da globalização, bem como de uma cobrança por mais eficiência da atuação do Estado. Com isso, surge a necessidade de o Estado trabalhar melhor com a informação. Daí surge o debate sobre importantes questões, como a da governança.

Nesse novo cenário de atuação estatal, altera-se a forma como o Estado exerce o poder. Braman (2006) aborda a importância do debate sobre política ${ }^{1}$ de informação no contexto de transformação do Estado de bem-estar burocrático em estado informacional.

\footnotetext{
${ }^{1}$ Em inglês policy. Cabe destacar a diferença entre os termos policy e politics, em inglês, ambos traduzidos para o português pelo termo "política". Segundo o dicionário Collins, policy refere-se a um cenário de
} 
Enquanto a política de informação está esteja entre as mais antigas formas de governança, há uma mudança de fase de mudança - uma mudança de estado - na medida em que dimensão para a qual os governos deliberadamente, explicitamente e consistentemente controlam a criação de informação, processamento, fluxos e uso para o exercício do poder ${ }^{2}$ (BRAMAN, 2006, p. 1, tradução nossa).

González de Gómez (2011) destaca que o tema da "sociedade da informação" é debatido fortemente nos anos 1990, em detrimento do debate da informação no contexto do Estado. Isso se deve, segundo a autora, ao surgimento de novas esferas transnacionais de interação para além-fronteiras estatais, e ao surgimento e fortalecimento de atores internacionais.

O Estado Informacional e o Estado-rede são manifestações do esforço conceitual para reformular, no cenário contemporâneo, as possibilidades e os limites de autonomia do Estado, a partir do crescente questionamento da previsibilidade, inteligibilidade e controle de seu domínio de intervenção, incluindo o próprio domínio da informação (GONZÁLEZ DE GÓMEZ, 2011, p. 186).

Há uma demanda da sociedade para uma ação do Estado no sentido de aumentar sua transparência. Entre as informações governamentais ganham destaque a informação legislativa $^{3}$ e as informações subsidiárias para a construção de políticas públicas ${ }^{4}$. 0 debate para a construção de políticas públicas democráticas depende de um amplo acesso à informação sobre o tema.

A precariedade da organização da informação governamental afeta a eficácia da formulação de políticas públicas, que não levam em consideração os requisitos de informação necessários tanto na sua formulação quanto ao suporte aos objetos desejados. Igualmente a organização da informação estatal é necessária à participação democrática como subsídio ao debate na esfera pública.

Braman (1994, p. 359) aponta três tipos de relação entre informação e poder: (1) informação no exercício direto do poder (como na propaganda ou enquetes da opinião pública); (2) informação como crítica às transformações do poder potencial na atualidade;

ideias ou planos que são usados como base para tomada de decisão, especialmente em Política, Economia ou negócios; e Politics, por sua vez, são as ações ou atividades que dizem respeito ao alcance e uso do poder em um país ou sociedade.

2 "While information policy is among the most ancient forms of governance, there has been a phase change-a change of state-in the extent to which governments deliberately, explicitly, and consistently control information creation, processing, flows, and use to exercise power."

${ }^{3}$ Leis, decretos, portarias e demais normas jurídicas em vigor.

${ }^{4}$ Informação que circula no debate político que visa à criação ou alteração da legislação. 
(3) informação como um recurso entre outros recursos críticos para a capacidade que determina o poder potencial de um agente (como no uso da informação burocrática para implementação de políticas governamentais ou conhecimento das condições das culturas como ferramenta de barganha).

Nesses relacionamentos, embora entre caminhos diferentes, informação é poder são interdependentes. Os fluxos de informação que influenciam a opinião pública (tipo 1) tão significantemente que os modos de produção são transformados (tipo 2) podem razoavelmente ser tratadas pelos economistas como inputs na economia - que é, como recursos (tipo 3). Nesse processo as regras sobre criação de informação, processamento, fluxos e uso são o ato altamente reflexivo de constituir condições sob as quais constituirão a nós mesmos (BRAMAN, 1994, p. 359).

O termo política é polissêmico e abarca o conjunto de objetivos que formam a ação governamental e condicionam a sua execução dentro de um dado Estado (um dado espaço), a orientação de uma determinada forma de gerenciamento, e habilidade de negociar e harmonizar interesses. Da mesma forma, há uma dificuldade de estabelecerse um conceito de política de informação, conforme relata González de Gómez (2011):

\begin{abstract}
O escopo e abrangência do que se denomina "política de informação" e, logo, dos estudos que a tenham como objeto seriam ainda mais difíceis de estabelecer. Pensada, por muitos, antes como meio e recurso que como domínio finalístico de políticas, para outros, uma política de informação só poderia ser, por razões intrínsecas ao seu papel social, uma política pública: no sentido pleno dos modos de sua elaboração, dos atores implicados, das condições de sua implementação e vigência e de sua dupla articulação com as outras políticas e com as esferas de sua intervenção (GONZÁLEZ DE GÓMEZ, 2011, p. 184).
\end{abstract}

Braman $(2006,2011)$ considera a definição de informação como força constitutiva na sociedade a mais apropriada. A partir dessa definição, a informação não é mero recurso e sim um poder na constituição da sociedade. A informação é parte do jogo político no Estado informacional. A política da informação é um termo "guarda-chuva" para leis, regulamentos e posições doutrinárias que tratam de informação, comunicação e cultura. Mais precisamente, assim se expressa:

A política de informação é composta por leis, regulamentos e posições doutrinárias - e outra tomada de decisão e práticas com efeitos constitutivos para toda a sociedade - que envolvem a criação de 
informação, processamento, fluxos, acesso e uso ${ }^{5}$ (BRAMAN, 2011, p. 3, tradução nossa).

Braman (2011, p. 3) aponta os seguintes critérios adotados na elaboração dessa definição: (1) validade por abranger uma variedade de instrumentos legais; (2) abrangência por essa definição buscar analisar diferentes assuntos por uma lente comum; (3) solidez teórica; (4) incorporação de metodologia operacional sendo facilmente incorporada a diversos métodos; e (5) facilidade de tradução para diversas línguas e audiências.

A definição de política de informação que melhor atende aos propósitos dessa pesquisa é apresentada por González de Gómez (1999, p. 69): “conjunto das ações e decisões orientadas a preservar e reproduzir, ou a mudar e substituir um Regime de Informação e podem ser tanto políticas táticas ou explícitas, micro ou macro-políticas”.

Braman (2004) trabalha o regime global da política informação constituído por novas instituições, ferramentas políticas e comportamentos. Esse regime envolve tanto atores estatais quanto não estatais; os regimes envolvem o governo, a governança (atores estatais e não estatais) e a governabilidade (contexto cultural e social). A análise de Braman dá ênfase, sobretudo, no aspecto legal que consolida e registra formalmente as políticas de informação.

Na análise de González de Gómez (2002),

[...] o conceito de 'regime de informação', que designaria um modo de produção informacional dominante em uma formação social, conforme o qual serão definidos sujeitos, instituições, regras e autoridades informacionais, os meios e os recursos preferenciais de informação, os padrões de excelência e os arranjos organizacionais de seu processamento seletivo, seus dispositivos de preservação e distribuição. Um "regime de informação" constituiria, logo, um conjunto mais ou menos estável de redes sociocomunicacionais formais e informais nas quais informações podem ser geradas, organizadas e transferidas de diferentes produtores, através de muitos e diversos meios, canais e organizações, a diferentes destinatários ou receptores, sejam estes usuários específicos ou públicos amplos (GONZÁLEZ DE GÓMEZ, 2002, p. 34).

Embora os regimes de informação tenham a participação de diversos atores estatais e não estatais -, o regime de informação em Defesa tem características

\footnotetext{
5 "Information policy is comprised of laws, regulations, and doctrinal positions - and other decision making and practices with society-wide constitutive effects - involving information creation, processing, flows, access, and use."
} 
diferenciadas dada a prerrogativa do Estado como detentor do monopólio do uso da força. A participação de atores não estatais se dá no âmbito do debate sobre a questão de Defesa, sendo, no entanto, as decisões dessa área tomadas no governo pelos mais diversos níveis hierárquicos.

\section{O DEBATE DA POLÍTICA DE DEFESA}

Após a promulgação da Constituição de 1988, o Brasil começa a trilhar novos caminhos na Democracia. Nesse contexto, o debate sobre as questões de Defesa, que era restrito principalmente aos agentes do Estado, passa a se estender a outros segmentos da sociedade, em especial ao político e ao acadêmico. Neste capítulo serão analisados os aspectos políticos que possibilitaram a ampliação do debate das questões de Defesa na história recente do Brasil: a Constituição de 1988, a criação no Ministério da Defesa, a publicação da Política de Defesa Nacional (PDN) e da Estratégia Nacional de Defesa (END).

A Constituição de 1988 é fundamental para a definição do papel das Forças Armadas. Durante a Assembléia Nacional Constituinte, houve um importante debate sobre a questão. A cultura política de um país consolida-se em torno da Constituição em vigor. Toda a cultura do país, sob a luz da própria história, amolda, em cada caso um tipo de leitura diferente para os mesmos princípios - tais como soberania do povo e direitos humanos -, os quais também se corporificam em outras constituições republicanas (HABERMAS, 2007, p. 141).

A missão das Forças Armadas fica consolidada, no artigo 142 da Constituição Federal de 1988, com a seguinte redação

Art. 142. As Forças Armadas, constituídas pela Marinha, pelo Exército e pela Aeronáutica, são instituições nacionais permanentes e regulares, organizadas com base na hierarquia e na disciplina, sob a autoridade suprema do Presidente da República, e destinam-se à defesa da Pátria, à garantia dos poderes constitucionais e, por iniciativa de qualquer destes, da lei e da ordem (BRASIL, 1988).

Entre os ministros militares, durante a Constituinte

Havia consenso a respeito dos principais itens da agenda militar para a Constituinte, embora pudesse haver maior ênfase de uma das forças em relação a algum ponto específico. Por exemplo, a manutenção do serviço 
militar obrigatório, que interessa principalmente ao Exército, e a manutenção do controle da aviação civil, ponto de honra para a Aeronáutica. Entre os pontos importantes, havia também posições contrárias a mudanças no status quo: contra a criação, naquele momento, do Ministério da Defesa; contra o fim da Justiça Militar; contra a ampliação do habeas data para a documentação do serviço de informações (CASTRO; D'ARAUJO, 2001, p. 18).

A Constituição de 1988 não altera significativamente a destinação constitucional das Forças Armadas. Naquela época, não se discute com profundidade, em termos constitucionais, o controle das Forças Armadas. A criação do Ministério da Defesa, por sua vez, não foi adiante em face aos argumentos que as Forças Armadas adotaram no seu discurso. Assim, as Forças Armadas brasileiras e os militares passam pela Assembléia Nacional Constituinte sem terem recebido alterações significativas nas suas prerrogativas.

A criação do Ministério da Defesa é a mudança mais acentuada no que se refere às Forças Armadas na estrutura republicana brasileira, uma vez que o Ministério da Defesa aglutina os quatro ministérios militares (Marinha, Exército, Aeronáutica e EstadoMaior das Forças Armadas) em apenas um. Atualmente, raros são os países que não reúnem suas Forças Armadas sob um único órgão de defesa, subordinado ao chefe do Poder Executivo.

Em 1995 o presidente Fernando Henrique Cardoso começa discutir a criação do Ministério da Defesa. Embora tenha pretendido criar o Ministério no seu primeiro mandato o Presidente só consegue fazê-lo no início do seu segundo mandato. A idéia éa aperfeiçoar o sistema de defesa nacional, formalizar uma política de defesa sustentável e integrar as três Forças, racionalizando as suas atividades. Em entrevista ao pesquisador Eliézer Oliveira, o Fernando Henrique Cardoso aponta suas razões para a criação do Ministério da Defesa.

Uma razão era para racionalização (custos, operações militares etc.). A outra razão: o novo ministério seria o símbolo da democratização, chegando o momento em que o ministério das forças de defesa seria civil. Sempre me preocupei que a questão da Defesa fosse debatida na sociedade (OLIVEIRA, 2005, p. 431-432).

Fernando Henrique Cardoso nomeia o senador Elcio Álvares ministro Extraordinário da Defesa em $1^{0}$ de janeiro de 1999, responsável pela implantação do órgão. Somente em 10 de junho de 1999 o Ministério da Defesa é oficialmente criado e o 
Estado-Maior das Forças Armadas extinto, com os ministérios da Marinha, do Exército e da Aeronáutica sendo transformados em Comandos ${ }^{6}$. A Emenda Constitucional no 23/1999 altera os art. 12 e 91 da Constituição Federal, com a introdução de referências ao ministro de Estado da Defesa.

O processo de concepção da Defesa como política de Estado está previsto na Política de Defesa Nacional (PDN) ${ }^{7}$ e na Estratégia Nacional de Defesa (END) ${ }^{8}$. Nesses documentos o tema da Defesa é apresentado como algo que envolve toda a sociedade brasileira, não sendo, portanto, de exclusivo interesse das Forças Armadas. Esse envolvimento pressupõe o estabelecimento do acesso à informação sobre o tema pela sociedade.

A Política de Defesa Nacional (PDN) destaca que:

Após um longo período sem que o Brasil participe de conflitos que afetem diretamente 0 território nacional, a percepção das ameaças está desvanecida para muitos brasileiros. Porém, é imprudente imaginar que um país com o potencial do Brasil não tenha disputas ou antagonismos ao buscar alcançar seus legítimos interesses. Um dos propósitos da Política de Defesa Nacional é conscientizar todos os segmentos da sociedade brasileira de que a defesa da Nação é um dever de todos os brasileiros (BRASIL, 2005, grifo nosso).

A participação da sociedade na temática de Defesa é incipiente porque o debate de Defesa é novo para os brasileiros. Entretanto, passos significativos foram dados na ampliação do debate. Nesse processo devem-se considerar as mudanças no regime de informação em face das mudanças no cenário político brasileiro e internacional. Há a participação de diversos atores, tais como militares, industriais de defesa, especialistas civis de Defesa, políticos, diplomatas, estudantes e população em geral.

Atualmente, as Forças Armadas são formalmente uma instituição que está harmonizada com o compromisso democrático do Estado e imbuída de um espírito de profissionalismo na defesa do Brasil. O poder político dispõe sobre a Política de Defesa Nacional (PDN) e a Estratégia Nacional de Defesa (END), que dão as linhas gerais para os comandantes atuarem nas respectivas forças. A subordinação do militar ao poder constitucional e legítimo orienta todo o contexto da Defesa Nacional.

\footnotetext{
${ }^{6}$ Cf. https://www.defesa.gov.br/index.php/historico-do-md.html

${ }^{7}$ Publicada pelo Decreto n. 5.484, de 30 de junho de 2005 (BRASIL, 2005a).

${ }^{8}$ Publicada pelo Decreto n. 6.703, de 18 de dezembro de 2008 (BRASIL, 2008).
} 
Vergottini (1998, p. 315-316) considera que a subordinação do estamento militar ao poder civil deriva de princípios organizadores como: (a) o comando presidencial das Forças Armadas; (b) a total isenção política das Forças Armadas; (c) submissão do ordenamento das Forças Armadas ao ordenamento geral do Estado; e (d) a intervenção das Forças Armadas unicamente a pedido do poder político. D’Araujo (2010, p. 108-109) evidencia que no Brasil passou a haver menos presença militar na política nacional a partir da Nova República (1985), e uma crescente aceitação de um novo padrão nas relações civil-militares.

No processo de construção de uma nova institucionalidade militar foram elaborados dois documentos importantes: a Política de Defesa Nacional, de 1996, reformulada em 2005, e a Estratégia Nacional de Defesa, de 2008.

A Política de Defesa Nacional (PDN) é uma declaração política de 1996, de tom diplomático e militar, na qual o Estado torna pública sua natureza estratégica e a organização da sua defesa. Esta proclamação, que se destina tanto ao campo internacional quanto à sociedade nacional, aborda as razões de Estado que condicionam a política mais radical a ser eventualmente concretizada - a guerra - para a preservação de um Estado enquanto entidade política soberana. Ou seja, a PDN é uma declaração de caráter nacional sobre a dimensão estratégia que um Estado deseja ter ou preservar no plano internacional. Nas últimas décadas, essas características políticas de defesa nacional têm sido adotadas em um número crescente de países (OLIVEIRA, 2005, p. 375).

O Ministério da Defesa elaborou e publicou em 2012 o Livro Branco de Defesa Nacional. Este é um documento público que expõe a visão do governo sobre o tema da Defesa, a ser divulgado para as comunidades nacional e internacional. Segundo o Decreto no 7.438/2011:

Art. 1ํ - O Livro Branco de Defesa Nacional é documento de caráter público, por meio do qual se permitirá o acesso ao amplo contexto da Estratégia Nacional de Defesa, em perspectiva de médio e longo prazos, que viabilize o acompanhamento do orçamento e do planejamento plurianual relativos ao setor (BRASIL, 2011).

A Lei complementar no 136, de 25 de agosto de 2010, define que o Livro Branco da Defesa deve abordar os seguintes temas: cenário estratégico para o século XXI; Política nacional de defesa; Estratégia nacional de defesa; Modernização das Forças Armadas; 
Racionalização e adaptação das estruturas de defesa; Suporte econômico da defesa nacional; As Forças Armadas: Marinha, Exército e Aeronáutica; Operações de paz e ajuda humanitária.

No Legislativo brasileiro existem duas comissões de Relações Exteriores e Defesa Nacional: uma na Câmara dos Deputados e outra no Senado Federal. Essas comissões têm papel importante no debate da Defesa Nacional.

Segundo o regimento interno do Senado Federal, compete à Comissão de Relações e Defesa Nacional, no que diz respeito especificamente à Defesa, emitir parecer sobre "Forças Armadas de terra, mar e ar, requisições militares, passagem de forças estrangeiras e sua permanência no território nacional, espaço aéreo e marítimo, declaração de guerra e celebração de paz (Const., art. 49, II)." (BRASIL, 2007, p. 83).

Segundo o regimento interno da Câmara dos Deputados, a sua Comissão de Relações Exteriores e de Defesa Nacional trata dos seguintes temas específicos da Defesa Nacional:

f) política de defesa nacional; estudos estratégicos e atividades de informação e contra-informação; segurança pública e seus órgãos institucionais; g) Forças Armadas e Auxiliares; administração pública militar; serviço militar e prestação civil alternativa; passagem de forças estrangeiras e sua permanência no território nacional; envio de tropas para o exterior; $h$ ) assuntos atinentes à faixa de fronteiras e áreas consideradas indispensáveis à defesa nacional; i) direito militar e legislação de defesa nacional; direito marítimo, aeronáutico e espacial; j) litígios internacionais; declaração de guerra; condições de armistício ou de paz; requisições civis e militares em caso de iminente perigo e em tempo de guerra; I) assuntos atinentes à prevenção, fiscalização e combate ao uso de drogas e ao tráfico ilícito de entorpecentes (BRASIL, 2000, p. 50).

Oliveira (2005, p. 106) considera que o Legislativo é mantido à margem do emprego da força militar do país. Quando há maior ou menor participação dos parlamentares, individualmente considerados, isto não implica alteração da regra geral: a responsabilidade pela defesa cabe ao presidente da República. Dessa forma, a participação do Poder Legislativo no debate das questões de defesa tem sido tímida e pouco priorizada em sua agenda.

\section{O CAMPO DE PESQUISA EM DEFESA}


Uma das características do novo regime de informação na área de Defesa no Brasil é a formação de um campo de pesquisa dedicado aos estudos das questões de Defesa. Pode-se destacar, nesse processo: o incentivo às pesquisas acadêmicas que é dado pelo Pró-defesa, a pesquisa e formação de pesquisadores da temática da Defesa no âmbito da Pós-Graduação em universidades brasileiras, associações acadêmicas que debatem a temática e promovem eventos e periódicos acadêmicos dedicados à temática.

O Programa Pró-Defesa incentiva projetos de pesquisa e formação de recursos humanos em nível de Pós-Graduação em Defesa Nacional. Esse incentivo visa ao desenvolvimento e consolidação do pensamento brasileiro na área, como se pode observar no objetivo geral apresentado em seu edital.

\subsection{OBJETIVO GERAL \\ O Pró-Defesa tem por objetivo estimular no País a realização de projetos conjuntos de pesquisa utilizando-se de recursos humanos e de infraestrutura disponíveis em diferentes IES e/ou demais instituições enquadráveis nos termos deste Edital, possibilitando a produção de pesquisas científicas e tecnológicas e a formação de recursos humanos pós-graduados em Defesa Nacional, contribuindo, assim, para desenvolver e consolidar o pensamento brasileiro na área (CAPES, 2005, 2008)}

Entre os objetivos específicos do programa destaca-se a criação de programas de pós-graduação em Defesa Nacional e a criação de áreas de concentração em programas existentes. Todos têm como finalidade estimular a ampliação da produção científica e o intercâmbio acadêmico nessa área, especialmente pelo intercâmbio de instituições civis e militares. Dessa forma, busca estender o debate entre especialistas civis e militares no desenvolvimento das pesquisas.

A temática da Defesa Nacional é ampla e abarca diversas visões. De modo a especificar o seu foco de atuação, define, em ambos os editais, suas áreas temáticas contempladas da seguinte forma em ambos os editais:

O PRÓ-DEFESA contempla a área de Defesa Nacional, entendida como a defesa da integridade do território, da soberania e dos interesses nacionais contra ameaças preponderantemente externas. Confere ênfase, ainda, a aspectos da defesa nacional que contribuam para a consolidação da estabilidade regional, para a manutenção da segurança internacional e para a projeção do Brasil no cenário internacional (CAPES, 2005, 2008).

Entretanto, cada edital estabeleceu áreas de prioridade. O primeiro edital (20052009) apresentou as seguintes prioridades: a) cenários regionais de segurança e defesa; 
b) análise e avaliação de políticas públicas de defesa nacional; c) estudos estratégicos (guerra, combate e logística) e doutrina militar; d) teoria e história da guerra; e) relações entre civis e militares e sociologia das forças armadas; f) ciência, tecnologia e defesa nacional; g) indústria de defesa e poder político; h) missões de paz; i) conceitos de segurança e defesa; j) teoria e análise de relações internacionais e de segurança internacional; e k) atividades subsidiárias das forças armadas (CAPES, 2005, p. 2).

O Segundo edital (2009-2012) relacionou como prioridades: a) políticas públicas e Defesa Nacional; b) orçamento e gestão de recursos de Defesa; c) desenvolvimento social e ações subsidiárias das Forças Armadas; d) cenários internacionais de Segurança e Defesa; e) ciência, tecnologia e inovação em Defesa Nacional; f) logística e mobilização voltadas para a Defesa Nacional; g) sociologia das Forças Armadas; h) estudos estratégicos em Defesa Nacional; e i) educação nacional e ensino militar (CAPES, 2008, p. 2-3).

Cabe destacar que o edital do Pró-Defesa 2 (2009-2012) dispõe sobre parcerias entre Instituições de Ensino Superior (IES) e a prioridade para parceria entre instituições civis e militares:

a) somente serão apoiados no âmbito do Pró-Defesa projetos que envolvam parcerias (redes ou consórcios) entre equipes de diferentes IES ou entre estas e outras instituições de ensino e/ou pesquisa em nível de pós-graduação que se enquadrem nos termos deste Edital. Será conferida prioridade a projetos que contemplem a parceria entre instituições civis e militares (CAPES, 2008, p. 3).

Esse requisito dá nova dinâmica às atividades de pesquisa permitindo um maior fluxo de informação entre instituições civis e militares. Outro requisito igualmente importante para ampliar o fluxo de informações no âmbito da Defesa é o uso de tecnologia da informação para a troca de informações entre os pesquisadores e a sociedade como consta nesse edital:

e) é desejável que o projeto tenha caráter multidisciplinar, e contemple o uso interativo de novas tecnologias da informação e da comunicação com vistas a estimular a formação de redes de pesquisadores e a troca de conhecimentos entre as instituições participantes;

f) é desejável que o projeto tenha em foco a disseminação de resultados (das pesquisas desenvolvidas) para o conjunto da sociedade brasileira, preferencialmente por meio da internet (CAPES, 2008, p. 4). 
É importante destacar também a formação da Associação Brasileira de Estudos de Defesa (ABED), que tem por finalidade congregar pesquisadores que desenvolvam estudos e pesquisas sobre Defesa Nacional, Segurança Nacional e Internacional. Entre os assuntos colocados em questão pela entidade estão os relativos à defesa nacional, à segurança nacional e internacional, à guerra e à paz, à História Militar, às relações entre Forças Armadas e sociedade, à ciência e tecnologia no âmbito da base industrial de defesa, entre outros.

A ABED é criada em 2005 por ocasião da reunião do Grupo de Trabalho "Forças Armadas, Estado e Sociedade" da Associação Nacional de Pós-Graduações em Ciências Sociais (ANPOCS), em Caxambu, MG. Foi fundada por pesquisadores e estudiosos pertencentes a diversas instituições de pesquisa e ensino em todo o Brasil. A iniciativa resulta do reconhecimento de que a área, com presença marcante no cenário acadêmico dos principais países do mundo, havia adquirido lugar expressivo no Brasil.

$\mathrm{Na}$ análise sobre a Defesa como campo, é importante considerar os periódicos que tratam do tema. O periódico serve de veículo de registro do conhecimento científico, e reflete a atualidade científica e técnica. Faz-se a indicação dos periódicos avaliados pela CAPES por meio do Qualis:

- E-Premissas: Revista de Estudos Estratégicos (UNICAMP) - ISSN 1981-1438 Avaliação Qualis/CAPES: Interdisciplinar - B4; História - B5; Sociologia - B5. Site: http://www.unicamp.br/nee/epremissas/index.htm

- A Defesa Nacional - ISSN 0011-7641 Avaliação Qualis/CAPES: História - B5; Direito - C; Interdisciplinar - C; Sociologia - C.

- Navigator - ISSN 0100-1248 Avaliação Qualis/CAPES: História - B4.

Site: http://www.revistanavigator.com.br/

- Revista Marítima Brasileira - ISSN: 0034-9860 Avaliação Qualis/CAPES: Ciência Política e Relações Internacionais B3; Engenharias I B4; Ciências biológicas B5; Direito - C; Zootecnia/recursos pesqueiros C.

- Revista da Escola de Guerra Naval (Ed. português) - ISSN: 1809-3191 Avaliação Qualis/CAPES: Direito - C.

Site: http://www.egn.mar.mil.br/arquivos/revistaEgn/revistaEgn.htm

- Pesquisa Naval - ISSN: 1414-8595 
Avaliação Qualis/CAPES: Engenharias III - B4; Interdisciplinar B4; Engenharias IV B5; Geociências B5; Administração, Ciências Contábeis e Turismo - C; Química C.

- Revista de Villegagnon (Impresso) - ISSN: 1981-0342

Avaliação Qualis/CAPES: Letras/linguística - B5.

- Revista da Escola Superior de Guerra - ISSN 0102-1788

Avaliação Qualis/CAPES: Ciência Política e Relações internacionais B2.

- PADECEME - ISSN 1677-1885

Publicada pela Escola de Comando e Estado-Maior do Exército

Avaliação Qualis/CAPES: Engenharias II - B5; História - B5.

- C\&T. Revista Militar de Ciência e Tecnologia - ISSN 0102-3543

Publicada pela Biblioteca do Exército Editora

Avaliação Qualis/CAPES: Engenharias II B3; Interdisciplinar - B3; Engenharias I B5;

Engenharias IV B5; Geociências B5; Química C.

- Revista Militares e Política - ISSN: 1982-6834

Publicada pelo Laboratório de Estudos sobre Militares na Política - LEMP/UFRJ

Avaliação Qualis/CAPES: História B3; Sociologia B3.

Site: http://www.lemp.ifcs.ufrj.br/revista/

- Revista do Instituto de Geografia e História Militar do Brasil - ISSN 0020-3890

Publicada pelo Instituto de Geografia e História Militar do Brasil

Avaliação Qualis/CAPES: História B3.

Site: http://ighmb.org/

- Tensões Mundiais ISSN 1809-3124

Avaliação Qualis/CAPES: Ciência Política e Relações Internacionais B3; Interdisciplinar

B3; Sociologia B3; Educação B5; História B5.

Site: www.tensoesmundiais.net

A pesquisa acadêmica das questões da Defesa é indispensável. Não se pode imaginar que a Defesa do Estado possa ser debatida apenas por agentes do Estado. A democracia depende da participação do maior número de segmentos da sociedade na construção de um efetivo debate sobre a política de Defesa, para o qual os diversos atores são convidados a participar. $A$ inclusão a Defesa como integrante da área do conhecimento acadêmico se enquadra nesse processo. A afirmação da democracia 
demanda o desenvolvimento da política de defesa em novos alicerces, ou seja, com a diversificação de atores que participem do debate.

\section{CONSIDERAÇÕES FINAIS}

A política de Defesa, assim como as demais políticas de Estado, requer o debate com a sociedade, por meio da qual ela possa expressar seus anseios. Nesse processo, a circulação de informações sobre a Defesa contribui para o debate, pois fornece subsídios para que os participantes tenham uma visão mais abrangente dos aspectos envolvidos.

O Estado é um ator privilegiado, trabalha com informações públicas e privadas sobre a população e sobre as instituições. Embora esse trabalho sempre seja presente na atuação estatal, o advento de novas tecnologias de informação e comunicação modifica a dinâmica da atuação do Estado de modo a trazer maior controle, agilidade e transparência aos processos administrativos. Por outro lado, essa mesma tecnologia possibilita ao cidadão um maior acesso às informações sobre o Estado e permite, assim, ter maior participação e no debate sobre as políticas de Estado. Nesse contexto, a Política de Defesa, como uma política de Estado, é construída tendo à disposição os recursos eletrônicos para difundir informação aos diversos segmentos da sociedade de modo que esses possam debatê-las.

A Constituição de 1988 consolida a democracia brasileira e cria um ambiente de estimulo ao debate sobre diversas áreas de atuação do governo, com um leque mais amplo de atores envolvidos. As questões de Defesa merecem uma análise sob dois aspectos. O primeiro referente à busca de um novo marco legal que registre a Política de Defesa do país em documentos públicos, que irão culminar na publicação do Livro Branco de Defesa Nacional. Este será um documento de referência sobre as atividades de Defesa.

O segundo aspecto é a formação de um corpo acadêmico que estude as questões de Defesa, que passa a ser um assunto relevante, a ser estudado no âmbito universitário, mediante programas de Pós-Graduação. Dessa forma, as questões de Defesa ganham uma análise mais aprofundada, com um alicerce teórico mais efetivo. Nesse aspecto destaca-se o intercâmbio entre o meio acadêmico e as instituições militares graças ao Pró-Defesa. 
O desenvolvimento da pesquisa acadêmica é significativo pelo acesso ao uso das tecnologias de informação e comunicação que possibilitam rapidez e intercâmbio de informação em diferentes pontos do vasto território brasileiro, tornando possível, inclusive, que o ensino e a pesquisa se realizem em convênio com instituições dispersas geograficamente.

Em ambos os casos evidencia-se a que intenção do debate político provoca mudanças no regime de informação na área da Defesa no contexto da democracia brasileira. No passado, por razões políticas, o tema se restringia ao âmbito governamental. A troca de informações entre o Estado e a sociedade era bastante limitada. Atualmente, em face da mudança das condições políticas, o regime de informação é marcado pela ampliação do debate, por meio de estudos acadêmicos e pela institucionalização da política de defesa.

Não restam dúvidas de que as mudanças nas circunstâncias políticas afetam fortemente o regime de informação. Como se pode observar o debate da temática de Defesa ganha nova dinâmica no contexto democrático. Nesse aspecto, tem-se um exemplo de como as circunstâncias políticas refletem na produção, disseminação e uso da informação, ou seja, refletem no que vem a ser o regime de informação vigente.

\section{REFERÊNCIAS}

ARAUJO, Luiz B. L. Pluralismo e justiça: estudos sobre Habermas. São Paulo: Loyola, 2010

BRAMAN, Sandra. The autopoietic state: communication and democratic potential in the net. Journal of the American Society for Information Science, Washington, v. 45, n. 6, p. 358-368, July 1994.

. The emergent global information policy regime. In: BRAMAN, Sandra (Ed.). The emergent global information policy regime. Houndsmills: Palgrave Macmillan, 2004. p. 12-37. Disponível em:

$<$ https://pantherfile.uwm.edu/braman/www/bramanpdfs/022_emergentregime.pdf >. Acesso em: 11 jun. 2010.

Changes of state: information policy and power. Cambridge: MIT Press, 2006.

. Defining information policy. Journal of Information Policy, University Park, v. 1, p. 1-5, 2011. Disponível em: <http://jip.vmhost.psu.edu/ojs/index.php/jp/index>. Acesso em: 5 maio 2011. 
BRASIL. Constituição (1988). Constituição da República Federativa do Brasil: texto constitucional promulgado em 5 de outubro de 1988, com as alterações em pelas emendas constitucionais $n^{\circ s} 1 / 92$ a 53/2006 e pelas emendas constitucionais de revisão $n^{\text {os }} 1$ a 6/94. Brasília: Senado Federal, Secretaria de Edições Técnicas, 2007.

BRASIL. Congresso. Senado Federal. Regimento interno: resolução n. 93, de 1970: texto editado em conformidade com a Resolução n. 18 de 1989, consolidado com as alterações decorrentes de emendas à Constituição, leis e resoluções posteriores, até 2006. Brasília: Senado Federal, 2007. 2 v.

BRASIL. Congresso. Câmara dos Deputados. Regimento interno da câmara dos deputados. Aprovado pela Resolução № 17, de 1989, e alterado pelas Resoluções nos 1, 3 e 10, de 1991; 22 e 24, de 1992; 25, 37 e 38, de 1993; 57 e 58, de 1994; 1, 77, 78 e 80, de 1995; 5, 8 e 15, de 1996; 33, de 1999; e 11, de 2000. 5. ed. Brasília: Câmara dos Deputados, Coordenação de Publicações, 2000.

BRASIL. Decreto no 5.484 de 30 de junho de 2005. Aprova a Política de Defesa Nacional, e dá outras providências. Diário Oficial [da] República Federativa do Brasil, Brasília, 1 jul. 2005a. Disponível em: <http://www.planalto.gov.br/ccivil_03/_Ato20042006/2005/Decreto/D5484.htm>. Acesso em: 15 out. 2009.

BRASIL. Decreto no 6.703 de 18 de dezembro de 2008. Aprova a Estratégia Nacional de Defesa, e dá outras providências. Diário Oficial [da] República Federativa do Brasil, Brasília, 19 dez. 2008. Disponível em:

$<$ http://www.mar.mil.br/diversos/estrategia_defesa_nacional_portugues.pdf >. Acesso em: 25 set. 2011.

BRASIL. Coordenação de Aperfeiçoamento de Pessoal de Nível Superior. Edital PróDefesa № 01 / 2005. Instruções para apresentação de projetos do programa de apoio ao ensino e à pesquisa científica e tecnológica em defesa nacional pró-defesa. Brasília, abr. 2005.

Edital Pró-Defesa № 01 / 2008. Instruções para apresentação de projetos do programa de apoio ao ensino e à pesquisa científica e tecnológica em defesa nacional pró-defesa. Brasília, abr 2008.

CASTRO, Celso; D’ARAUJO, Maria Celina. Militares e política na Nova República. Rio de Janeiro: FGV, 2001.

CAPES. Edital Pró-Defesa n. 01/2005. Instruções para Apresentação de Projetos do Programa de Apoio ao Ensino e à Pesquisa Científica e Tecnológica em Defesa Nacional. Disponível em: <http://www.capes.gov.br/images/stories/download/bolsas/

Edital_ProDefesa.pdf $>$. Acesso em: 21 set. 2011.

CAPES. Edital Pró-Defesa n. 01/2008. Instruções para Apresentação de Projetos do Programa de Apoio ao Ensino e à Pesquisa Científica e Tecnológica em Defesa Nacional. Disponível em: <http://www.capes.gov.br/images/stories/download/bolsas/

Edital_ProDefesa.pdf>. Acesso em: 21 set. 2011. 
GONZÁLEZ DE GÓMEZ, Maria Nélida. Da organização do conhecimento às políticas de informação. Informare, Rio de Janeiro, v. 2, n. 2, p. 58-66, jan./dez. 1996.

Da política de informação ao papel da informação na política contemporânea.

Revista Internacional de Estudos Políticos, Rio de Janeiro, v. 1, n. 1, p. 67-93, abr. 1999.

Novos cenários políticos para a informação. Ciência da Informação, Brasília, v. 31, n. 1, p. 27-40, jan./abr. 2002.

Informação, conhecimento e poder: do ponto de vista das relações entre política, economia e linguagem. In. ALBAGLI, Sarita; MACIEL, Maria Lucia (Org.). Informação, conhecimento e poder: mudança tecnológica e inovação social. Rio de Janeiro:

Garamond, 2011. p. 183-210.

HABERMAS, Jürgen. Pensamento pós-metafísico: estudos filosóficos. Rio de Janeiro: Tempo Brasileiro, 2002.

Direito e democracia: entre facticidade e validade. Rio de Janeiro, Tempo Brasileiro, 2003. 2. v.

A inclusão do outro: estudos de teoria política. 3. ed. São Paulo: Loyola, 2007.

LUHMANN, Niklas. Social systems. Stanford: Stanford University Press, 1995.

Introdução à teoria dos sistemas. Petrópolis: Vozes, 2009.

OLIVEIRA, Eliézer Rizzo de. Democracia e defesa nacional: a criação do Ministério da Defesa na presidência de FHC. Barueri: Manole, 2005.

VANDENBERGHE, Frédéric. Os livros que Habermas não escreveu. Boletim CEDES, Rio de Janeiro, dez./jan. 2010. Disponível em:

<http://cedes.iesp.uerj.br/PDF/11janeiro/Resenha\%20-\%20Vandenberghe.pdf>. Acesso em: 21 set. 2011.

VERGOTTINI, Giuseppe. Defesa. In: BOBBIO, Norberto; MATTEUCCI, Nicola; PASQUINO, Gianfranco (Org.). Dicionário de Política. 11. ed. Brasília: UnB, 1998. p. 312-318.

\section{Title}

Information and defense policy: the debate in Brazil after 1988

\section{Abstract}

Introduction: In this work is presented as the available information on Defense subsidize society in policy debate of Defense, which actors who engage in the debate and how they get information and transform during the debate. 
Objective: Identify elements for discussion of the underlying information system for the production of defense studies in Brazil in a democratic context.

Methodology: Research methods and procedures proposed include: (1) the analysis of legislation on Defense in Brazil in order to emphasize the role of information in this context, and (2) the analysis of the academic field of Defense in Brazil.

Results: It is observed that the area of Defense is increasingly present in the political scene and in the strategic decisions of the government.

Conclusions: Can notice significant changes in relation to decision-making on defense. Although it was designed as a state policy and planned on National Defense Policy (NDP) and the National Defense Strategy (END), the defense policy of the company has received an even incipient, although there are significant advances.

Keywords: Habermas. Defense policy. Information regime. Brazil.

\section{Título}

Información y política de defensa: el debate en Brasil a partir de 1988

\section{Resumen}

Introducción: En este trabajo se presenta como la información disponible sobre Defensa subsidiar la sociedad en el debate de la política de Defensa, que los actores que participan en el debate y la forma en que obtienen información y se transforman durante el debate.

Objetivo: Identificar los elementos para discutir las modalidades de la información subyacente en la elaboración de estudios de defensa de Brasil en un contexto democrático.

Metodología: Los métodos de investigación y los procedimientos propuestos incluyen: (1) el análisis de la legislación en materia de Defensa de Brasil con el fin de destacar el papel de la información en este contexto, y (2) el análisis del campo académico de Defensa de Brasil.

Resultados: Se observa que el área de Defensa está cada vez más presente en la escena política y en las decisiones estratégicas del gobierno.

Conclusiones: Se puede notar cambios significativos en relación con la toma de decisiones en materia de defensa. A pesar de que fue diseñado como una política de Estado y planeó sobre la política de Defensa Nacional (PND) y la Estrategia Nacional de Defensa (END), la política de defensa de la empresa ha recibido una aún incipiente, aunque hay avances significativos.

Palabras clave: Habermas. La política de defensa. Régimen informativo. Brasil.

Recebido em: 10.09.2013

Aceito em: 30.11 .2013 